\title{
Synthesis of Multibranched Polymers by Linking Reactions of Linear Block Copolymers with Pendant Vinyl Groups by Conventional Radical Polymerization
}

\author{
Shokyoku KANAOKA, ${ }^{\dagger \dagger \dagger}$ Chieko Koyama, and Toshinobu Higashimura \\ Department of Materials Science, School of Engineering, The University of Shiga Prefecture, \\ 2500 Hassaka, Hikone 522-8533, Japan
}

(Received September 9, 2002; Accepted December 12, 2002)

\begin{abstract}
Polymer linking reactions of block copolymers with pendant vinyl groups were examined based on conventional radical reaction. For example, sequential living cationic polymerization with the $\mathrm{HCl} / \mathrm{ZnCl}_{2}$ initiating system gave a block copolymer of isobutyl vinyl ether [IBVE, $\mathrm{CH}_{2}=\mathrm{CHOCH}_{2} \mathrm{CH}\left(\mathrm{CH}_{3}\right)_{2}$ ] and a vinyl ether with the methacrylate-type double bond [VEM, $\mathrm{CH}_{2}=\mathrm{CHOCH}_{2} \mathrm{CH}_{2} \mathrm{OCOC}\left(\mathrm{CH}_{3}\right)=\mathrm{CH}_{2}$ ]. The resulting block copolymer $[\mathrm{DP}(\mathrm{IBVE})=15-30, \mathrm{DP}(\mathrm{VEM})=5-10]$ is treated with $2,2^{\prime}$-azobisisobutyronitrile (AIBN) in toluene at $60^{\circ} \mathrm{C}$ to give a soluble polymer with multibranched structures. The $M_{\mathrm{w}}\left[M_{\mathrm{w}}(\mathrm{LS})\right]$ of the product star polymers determined by GPC online multiangle laser light scattering (GPC-MALLS), and the number of branches calculated from $M_{\mathrm{w}}(\mathrm{LS})$ ranged from $3.5 \times 10^{4}$ to $34 \times 10^{4}$, and from 15 to 140 , respectively. This is a possible method for the preparation of functionalized nanospheres.

KEY WORDS Multibranched Polymer / Cationic Polymerization / Radical Polymerization / Living Polymerization / Vinyl Ether / 2,2'-Azobisisobutyronitrile(AIBN) /
\end{abstract}

Star-shaped polymers with many short arms can be nanospheres or "crew-cut" type star polymers, which have attract much attention in recent years. There are several ways to synthesize star-shaped polymers, among which linking reactions of living polymers with bifunctional vinyl compounds are suited for the preparation of star polymers with many arms. ${ }^{1}$ This method is now applicable to living cationic, ${ }^{2}$ radical, ${ }^{3}$ ringopening metathesis polymerization, ${ }^{4}$ etc., not to speak of the anionic counterpart, ${ }^{1,5}$ which gave the first example of star polymers a couple of decades ago. We have recently synthesized nanospheres and/or "crewcut" star polymers based on living cationic polymerization of vinyl ethers. ${ }^{6}$ All the synthetic techniques, however, require a rather sophisticated system and/or restricted reaction conditions.

Nanospheres or "crew-cut" type star polymers with various types of functional groups may also be prepared by linking reactions of a separately prepared short block copolymer with several pendant vinyl groups. With conventional radical polymerization that is commonly employed in industries, there are indeed examples of the synthesis of nanospheres by linking reactions of block copolymers having a segment with pendant vinyl groups prepared by living anionic polymerization, ${ }^{7}$ in addition to the polymerization of a macromonomer with the terminal vinyl group. ${ }^{8,9} \mathrm{Few}$ of them, however, consist of polymer chains with protic polar functional groups, such as hydroxyl, carboxyl.

To prepare functionalized nanospheres, it is required to prepare a block copolymer with polar functions based on living polymerization. In cationic polymerization, living polymers of a variety of vinyl ethers (VEs) with a polar pendant group can readily be prepared, ${ }^{10}$ and among those monomers is included a VE with the pendant methacrylate moiety [VEM; $\left.\mathrm{CH}_{2}=\mathrm{CHOCH}_{2} \mathrm{CH}_{2} \mathrm{OCOC}\left(\mathrm{CH}_{3}\right)=\mathrm{CH}_{2}\right],{ }^{11}$ whose methacrylic vinyl group remains intact during living cationic polymerization through a vinyl ether function. Thus, we examined linking reactions of block copolymers containing VEM units, prepared by cationic polymerization, via conventional radical polymerization.

As illustrated in Scheme 1, a block copolymer 1 is prepared from the sequential living polymerization of VEM and isobutyl VE [IBVE; $\left.\mathrm{CH}_{2}=\mathrm{CHOCH}_{2} \mathrm{CH}\left(\mathrm{CH}_{3}\right)_{2}\right]$ with the HCl-IBVE adduct $/ \mathrm{ZnCl}_{2}$ initiating system. The treatment of the resulting block copolymer 1 with 2,2'-azobisisobutyronitrile (AIBN) may give a star polymer with many arms (2). This article focuses on the feasibility of the methodology outlined in Scheme 1 and the factors that may affect the molecular weight and the arm number $(f)$ of star polymer $\mathbf{2}$.

\footnotetext{
${ }^{\dagger}$ To whom correspondence should be addressed (Fax: +81-6-6850-5448, E-mail: kanaoka@chem.sci.osaka-u.ac.jp).

${ }^{\dagger}$ Present address: Department of Macromolecular Science, Graduate School of Science, Osaka University, Toyonaka 560-0043, Japan.
} 

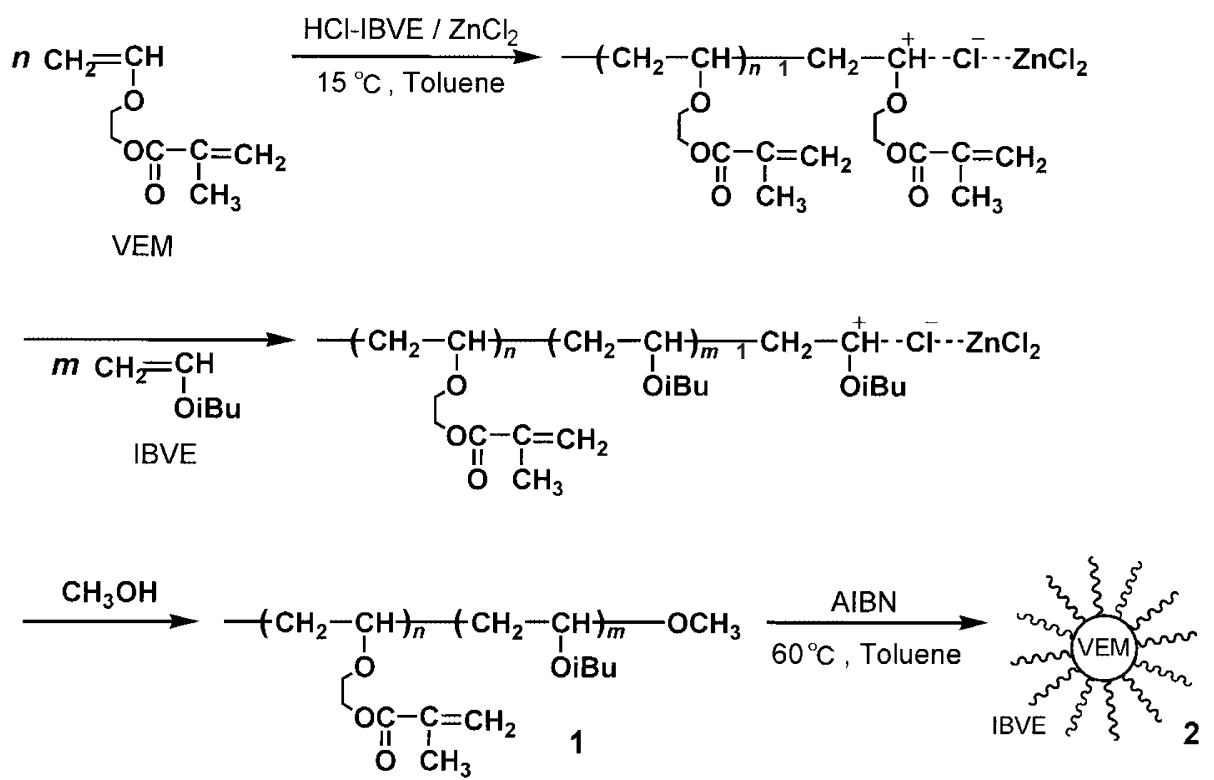

Scheme 1.

\section{EXPERIMENTAL}

\section{Materials}

IBVE (Tokyo Chemical Industry, Co., Ltd.) and VEM, prepared as previously reported, ${ }^{11}$ were dried overnight with potassium hydroxide (pellets), and they were purified by double distillation over calcium hydride. These monomers were stored into a brown ampule in a refrigerator. The HCl-IBVE adduct was prepared by bubbling dry $\mathrm{HCl}$ gas into a hexane solution of IBVE according to the literature method, ${ }^{12}$ and its hexane solution was stored into a brown ampule at $-80^{\circ} \mathrm{C} . \mathrm{ZnCl}_{2}$ (Aldrich, $1.0 \mathrm{M}$ solution in diethyl ether) and AIBN (Wako) were used as received. Toluene (polymerization solvent), carbon tetrachloride and bromobenzene (internal standards for gas chromatography in determining IBVE and VEM conversions, respectively) were washed by usual methods and distilled at least twice over calcium hydride before use. Commercially available anhydrous diethyl ether was distilled once over $\mathrm{LiAlH}_{4}$ before use.

\section{Procedures}

Sequential living cationic polymerizations were carried out under dry nitrogen in a baked flask with a three-way stopcock in toluene. The reactions were initiated by adding sequentially a prechilled adduct solution $\left(0.5 \mathrm{~mL}\right.$ in toluene) and a $\mathrm{ZnCl}_{2}$ solution $(0.5 \mathrm{~mL}$ in diethyl ether) to a monomer solution $(9.0 \mathrm{~mL}$ in toluene) at polymerization temperature. After the firststage polymerization had reached $c a$. $100 \%$ conversion, a toluene solution of a second monomer $(2.0 \mathrm{~mL})$ was added, and the reaction mixture was quenched with prechilled methanol ( $c a .2 \mathrm{~mL}$ ) containing a small amount of ammonia. The quenched reaction mixtures were washed with water at least 3 times. After the solvents were removed by evaporation under reduced pressure, the polymers were dried under vacuum overnight at room temperature.

Linking reactions were carried out under dry nitrogen in a flask with a three-way stopcock in toluene. The reactions were initiated by an AIBN solution $(0.4 \mathrm{~mL}$ in toluene) to a solution ( $1.6 \mathrm{~mL}$ in toluene) of $\mathbf{1}$ at reaction temperature, and terminated by cooling the reaction mixture to $0{ }^{\circ} \mathrm{C}$. Product polymers were recovered by evaporating the solvent.

\section{Polymer Characterization}

The weight-average molecular weight $\left(M_{\mathrm{w}}\right)$ of some samples were determined by multiangle laser light scattering (MALLS) in chloroform at $40^{\circ} \mathrm{C}$ on a Dawn E instrument (Wyatt Technology; Ga-As laser, $\lambda=$ $690 \mathrm{~nm})$. The $\mathrm{d} n / \mathrm{d} c$ of the polymers were ranged from $3.3 \times 10^{-2}$ from $4.1 \times 10^{-2} \mathrm{~mL} \mathrm{~g}^{-1}$. Gel permeation chromatography (GPC) was performed in chloroform (flow rate: $1.0 \mathrm{~mL} \mathrm{~min}^{-1}$ ) at $40{ }^{\circ} \mathrm{C}$ using a Shimadzu LC-10A liquid chromatograph system equipped with a Shimadzu LC-10AD pump, 3 polystyrene gel columns (Shodex K-803, 804, and 805), and refractive index/ultraviolet dual detectors. The weightaverage molecular weight $\left(M_{\mathrm{w}}\right)$ and polydispersity ratio $\left(M_{\mathrm{w}} / M_{\mathrm{n}}\right)$ of the polymers were calculated from chromatographs relative to commercial polystyrene standards of which molecular weights range from $5.0 \times 10^{3}$ to $1.5 \times 10^{6}$. 

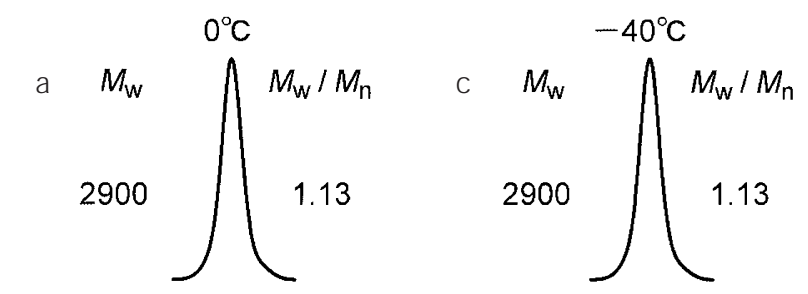

( b)

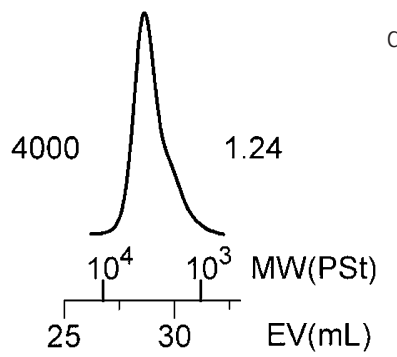

d)

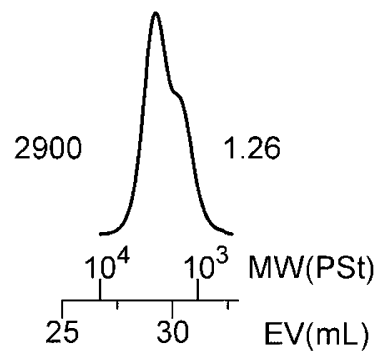

Figure 1. MWD curves of IBVE-VEM block copolymers and their precursor poly(IBVE) obtained from the sequential polymerization of IBVE and VEM with $\mathrm{HCl}-\mathrm{IBVE} / \mathrm{ZnCl}_{2}$ in toluene at $0{ }^{\circ} \mathrm{C}$ (a and $\mathrm{b}$ ) and $-40{ }^{\circ} \mathrm{C}$ (c and d): (a and c) starting poly(IBVE), $[\mathrm{IBVE}]_{0}=0.30 \mathrm{~mol} \mathrm{~L}^{-1},[\mathrm{HCl}-\mathrm{IBVE}]_{0}=10.0 \mathrm{mmol} \mathrm{L}^{-1}$. $\left[\mathrm{ZnCl}_{2}\right]_{0}$ : (a) $0.20 \mathrm{mmol} \mathrm{L}^{-1}$; (c) $2.0 \mathrm{mmol} \mathrm{L}{ }^{-1}$; (b and d) products obtained by the polymerization VEM from the living ends of sample a and c, respectively. IBVE/VEM feed ratio $=30 / 10$.

\section{RESULTS AND DISCUSSION}

Synthesis of Block Copolymers with a Pendant Methacrylate Moiety

Block copolymers of isobutyl vinyl ether (IBVE) and a VE with a pendant methacrylate group were prepared based on living cationic polymerization using the $\mathrm{HCl}$-IBVE adduct $/ \mathrm{ZnCl}_{2}$ initiating system. We first examined the synthesis of block copolymers by polymerizing IBVE first and then VEM in toluene at -40 and $0{ }^{\circ} \mathrm{C}$. The first-stage polymerization of IBVE gave living polymers with narrow molecular weight distribution (MWD) independently of reaction temperature [Figures 1a and 1c]. On the addition of VEM, its polymerization ensued immediately and completed in $1.5 \mathrm{~h}$ at $0{ }^{\circ} \mathrm{C}$, whereas conversion of VEM reached at most ca. $70 \%$ in $19 \mathrm{~h}$ at $-40^{\circ} \mathrm{C}$. The MWD of both product polymers show a shoulder in the lower molecular weight region [Figures $1 \mathrm{~b}$ and $1 \mathrm{~d}$ ], whose molecular weight is smaller than even that of homopoly(IBVE).

When a more reactive monomer is first polymerized, an additional dose of an activator should often be added in living cationic polymerization of vinyl ethers, which is the case with the polymerization sequence described above. A slow initiation of the second stage polymerization would cause a chain transfer reaction to give homopoly(VEM) with low molecular weight, which may occur frequently at a lower temperature where the polymerization of a less reactive monomer is much retarded.

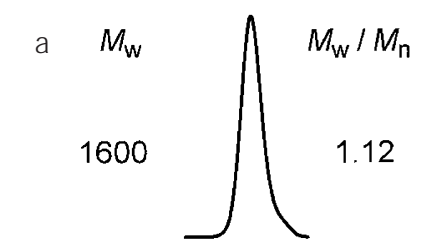

( b)

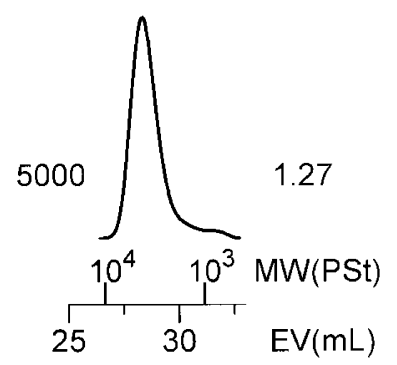

Figure 2. MWD curves of VEM-IBVE block copolymer 1 and its precursor poly(VEM) obtained from the sequential polymerization of VEM and IBVE with $\mathrm{HCl}-\mathrm{IBVE} / \mathrm{ZnCl}_{2}$ in toluene at $-15^{\circ} \mathrm{C}$ : (a) starting poly(VEM), $[\mathrm{VEM}]_{0}=0.10 \mathrm{~mol} \mathrm{~L}^{-1}$, [HClIBVE $]_{0}=10.0 \mathrm{mmol} \mathrm{L}^{-1},\left[\mathrm{ZnCl}_{2}\right]_{0}=1.0 \mathrm{mmol} \mathrm{L}^{-1}$; (b) block copolymer 1 from sample A. VEM/IBVE feed ratio $=10 / 30$.

Thus, the reverse sequence of block copolymerization was examined for VEM and IBVE (see Scheme 1).

Since polymerization of VEM is significantly retarded at $-40{ }^{\circ} \mathrm{C}$, VEM was polymerized in toluene at $-15^{\circ} \mathrm{C}$, where monomer conversion reached over $90 \%$ in $8 \mathrm{~min}$. On the addition of IBVE, a secondstage polymerization was triggered and was completed in 6 min. Figure 2 shows MWD curves of the product polymer and its precursor poly(VEM). The poly(VEM) has a narrow MWD [Figure 2a]. After the addition of IBVE, the MWD curve clearly shifted toward the higher molecular weight, and the polydispersity remained narrow [Figure $2 b]$.

\section{Linking Reaction of Block Copolymer 1 with a Radical Initiator}

The linking reactions of block copolymers $\left[\right.$ IBVE/VEM mol ratio $=30 / 10 ; M_{\mathrm{n}}=3.90 \times 10^{3}$, $\left.M_{\mathrm{w}} / M_{\mathrm{n}}=1.27\right]$ were examined with varying concentration of AIBN in toluene at $60^{\circ} \mathrm{C}$. In $24 \mathrm{~h}$, no gelation occurred during the reaction irrespective of AIBN concentration to yield products soluble in toluene and chloroform. The molecular weight of product polymers $\left[M_{\mathrm{w}}(\mathrm{GPC})=2.4-4.0 \times 10^{4}\right]$ were clearly higher than that of the starting block copolymer (Figure 3), although some amount of the block copolymer remained unreacted. The $M_{\mathrm{w}}(\mathrm{GPC})$ of the polymers decreased as the concentration of AIBN was raised. The conversion of the starting block copolymer showed a similar trend, and the conversion, which was $88 \%$ at $20 \mathrm{mmol} \mathrm{L}^{-1}$ of AIBN, lowered to $76 \%$ at $100 \mathrm{mmol} \mathrm{L}^{-1}$.

Linking reactions were examined with block copoly- 


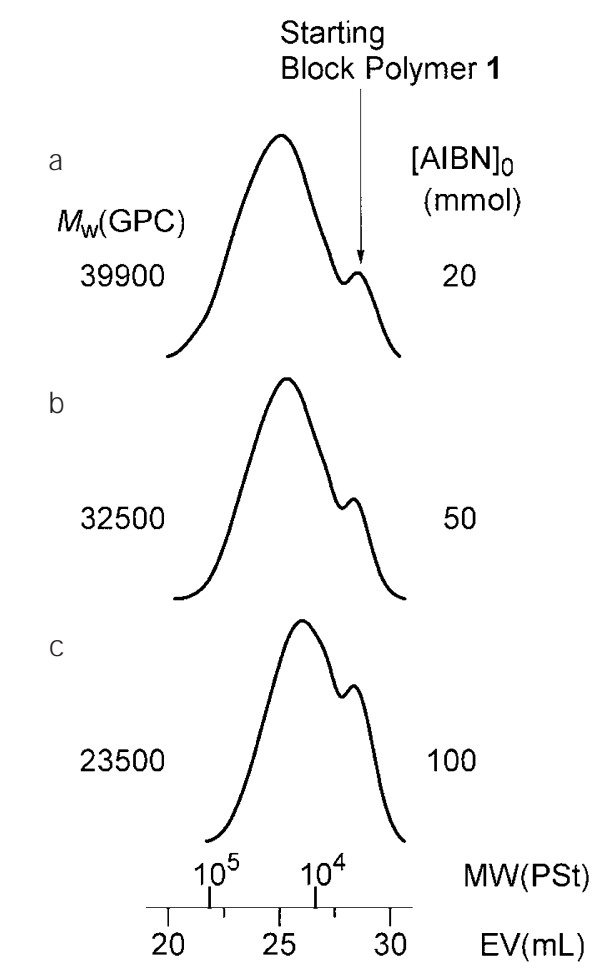

Figure 3. MWD curves of the products obtained by the treatment of block copolymer 1 (IBVE/VEM = 30/10) with AIBN in toluene at $60^{\circ} \mathrm{C}:[\mathbf{1}]_{0}=10.0 \mathrm{mmol} \mathrm{L}^{-1}$. [AIBN $]_{0}$ : (a) $20.0 \mathrm{mmol} \mathrm{L}^{-1}$; (b) $50.0 \mathrm{mmol} \mathrm{L}^{-1}$; (c) $100 \mathrm{mmol} \mathrm{L}^{-1}$.

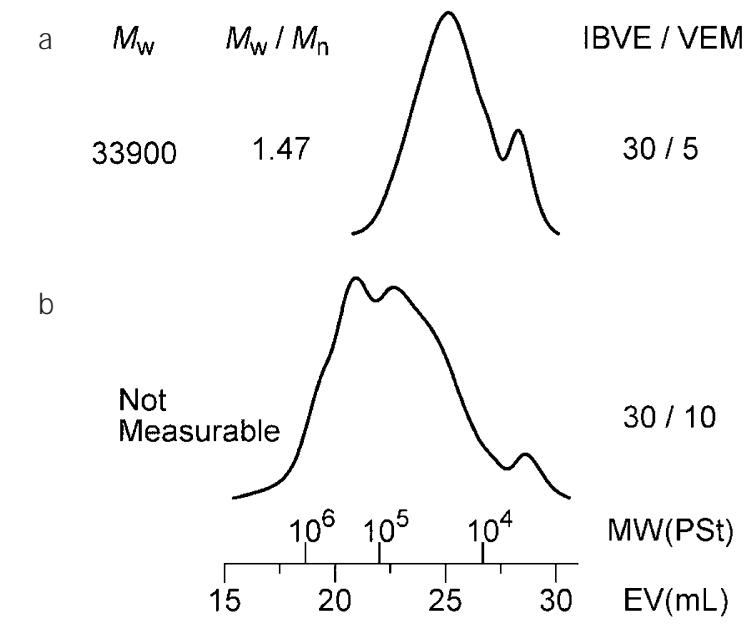

Figure 4. MWD curves of the products obtained by the treatment of block copolymer 1 with AIBN in toluene at $60{ }^{\circ} \mathrm{C}:[1]_{0}=$ $20.0 \mathrm{mmol} \mathrm{L}^{-1},[\mathrm{AIBN}]_{0}=20.0 \mathrm{mmol} \mathrm{L}^{-1}$. IBVE/VEM ratio in $\mathbf{1}$ : (a) $30 / 5$; (b) $30 / 10$.

mers with varying length of the VEM segment in a block copolymer [IBVE/VEM $=30 / 5\left(M_{\mathrm{n}}=3.78 \times 10^{3}\right.$, $\left.\left.M_{\mathrm{w}} / M_{\mathrm{n}}=1.25\right), 30 / 10\right]$. At a constant concentration of block copolymers $\left([\right.$ block $\left.]=20.0 \mathrm{mmol} \mathrm{L}^{-1}\right)$, a high molecular weight polymer $\left[M_{\mathrm{w}}(\mathrm{GPC})=3.39 \times 10^{4}\right.$, $\left.M_{\mathrm{w}} / M_{\mathrm{n}}=1.47\right]$ was obtained when $n$ was 5 (Figure 4). With the longer VEM segment $(n=10)$, the $M_{\mathrm{w}} / M_{\mathrm{n}}$ increased so much that the molecular weight of a part of product polymers exceed the exclusion limit of the columns employed for GPC herein, although the $M_{\mathrm{w}}$ and conversion of block copolymers increased.

In general, the molecular weight of star polymers via linking reactions of living polymers with divinyl compounds is influenced by the concentration of living polymers and/or divinyl compounds. Thus, we examined the effects of the overall concentration and number of vinyl groups on the molecular weight of product polymers (Table I). With a given length of VEM, the $M_{\mathrm{w}}$ of product polymers increased with the concentration of a starting block copolymer. When the overall concentration of vinyl groups was constant, the $M_{\mathrm{w}}$ of product polymers became higher in the reaction of a block copolymer with a larger $\mathrm{DP}_{\mathrm{n}}$ of VEM. The larger vinyl concentration and $\mathrm{DP}_{\mathrm{n}}$ of VEM $\left(200 \mathrm{mmol} \mathrm{L}^{-1}\right.$, IBVE/VEM = 30/10), however, gave an ill-defined product polymer with extremely high molecular weight as mentioned above (see Figure 4).

\section{Characterization of Multibranched Polymers}

Figure 5 shows ${ }^{1} \mathrm{H}$ NMR spectra of a product polymer (IBVE/VEM $=30 / 5)$ and its starting block copolymer. The spectrum of the starting block copolymer exhibits the absorptions assignable to the methylene protons (peak b) adjacent to the ester group and the vinyl protons (peak c) in the VEM units, in addition to those of the IBVE units (peak a, etc.). Although some vinyl groups (peak c) remained unreacted, it is difficult to determine how much they did, because of the broadening of their signals that stems from the restriction of their thermal motion due to a tightly cross-linking structure of a central core. This is also the case with the newly formed ester moieties whose signal are very broad [peak b, Figure 5b], which, in turn, gives a piece of evidence of the formation of multibranched polymers with microgel core via the reaction outlined in Scheme 1.

The weight-average molecular weight $\left[M_{\mathrm{w}}(\mathrm{LS})\right]$ of the product polymers was determined by multiangle laser light scattering (MALLS) in chloroform at $40^{\circ} \mathrm{C}$ (see Experimental Section). On the basis of the $M_{\mathrm{w}}(\mathrm{LS})$ value, the number $(f)$ of arms per molecule was calculated from the following relation:

$$
f=M_{\mathrm{w}}(\mathrm{LS}) /[\mathrm{FW}(\mathrm{IBVE}) \times m+\mathrm{FW}(\mathrm{VEM}) \times n]
$$

where FW(IBVE) and FW(VEM) are formula weight of IBVE and VEM, respectively; and $m$ and $n$ represent the degree of polymerization of IBVE and VEM segments in a block copolymer, respectively.

As shown in Table I, the arm number ranges from 15 to 140 and $M_{\mathrm{w}}(\mathrm{LS})$ from $5.9 \times 10^{4}$ to $19.1 \times 10^{4}$. Figure 6 plots the number of arms against the concentration of block copolymers. Irrespective of $\mathrm{DP}_{\mathrm{n}}$ of the VEM 
Table I. Characterization of star-shaped poly(IBVE) by GPC-MALLS ${ }^{\mathrm{a}}$

\begin{tabular}{|c|c|c|c|c|c|c|}
\hline \multirow{2}{*}{$\begin{array}{l}\text { Entry } \\
\text { No. }\end{array}$} & \multirow{2}{*}{ IBVE/VEM } & \multirow{2}{*}{$\begin{array}{c}\quad[\mathbf{1}]_{0} \\
\mathrm{mmol} \mathrm{L}\end{array}$} & \multicolumn{2}{|c|}{$M_{\mathrm{w}} \times 10^{-4}$} & \multirow{2}{*}{$M_{\mathrm{w}} / M_{\mathrm{n}}$} & \multirow{2}{*}{$f^{b}$} \\
\hline & & & $\mathrm{LS}^{\mathrm{c}}$ & $\mathrm{GPC}^{\mathrm{d}}$ & & \\
\hline 1 & $15 / 5$ & 20 & 3.46 & 2.17 & 1.50 & 14 \\
\hline 2 & $15 / 5$ & 30 & 11.5 & 5.95 & 2.21 & 48 \\
\hline 3 & $15 / 5$ & 40 & 33.7 & 15.4 & 4.02 & 140 \\
\hline 4 & $30 / 5$ & 20 & 5.89 & 3.39 & 1.47 & 15 \\
\hline 5 & $30 / 5$ & 30 & 13.7 & 6.28 & 1.87 & 36 \\
\hline 6 & $30 / 5$ & 40 & 19.1 & 9.44 & 2.30 & 49 \\
\hline
\end{tabular}

${ }^{\mathrm{a}}[\mathrm{AIBN}]_{0}=20.0 \mathrm{mmol} \mathrm{L}^{-1}$; in toluene at $60^{\circ} \mathrm{C}$ for $24 \mathrm{~h} .{ }^{\mathrm{b}} \mathrm{The}$ number of arms per molecule. ${ }^{\mathrm{c}}$ Determined by MALLS. ${ }^{\mathrm{d}}$ Determined by gel permeation (size-exclusion) chromatography.
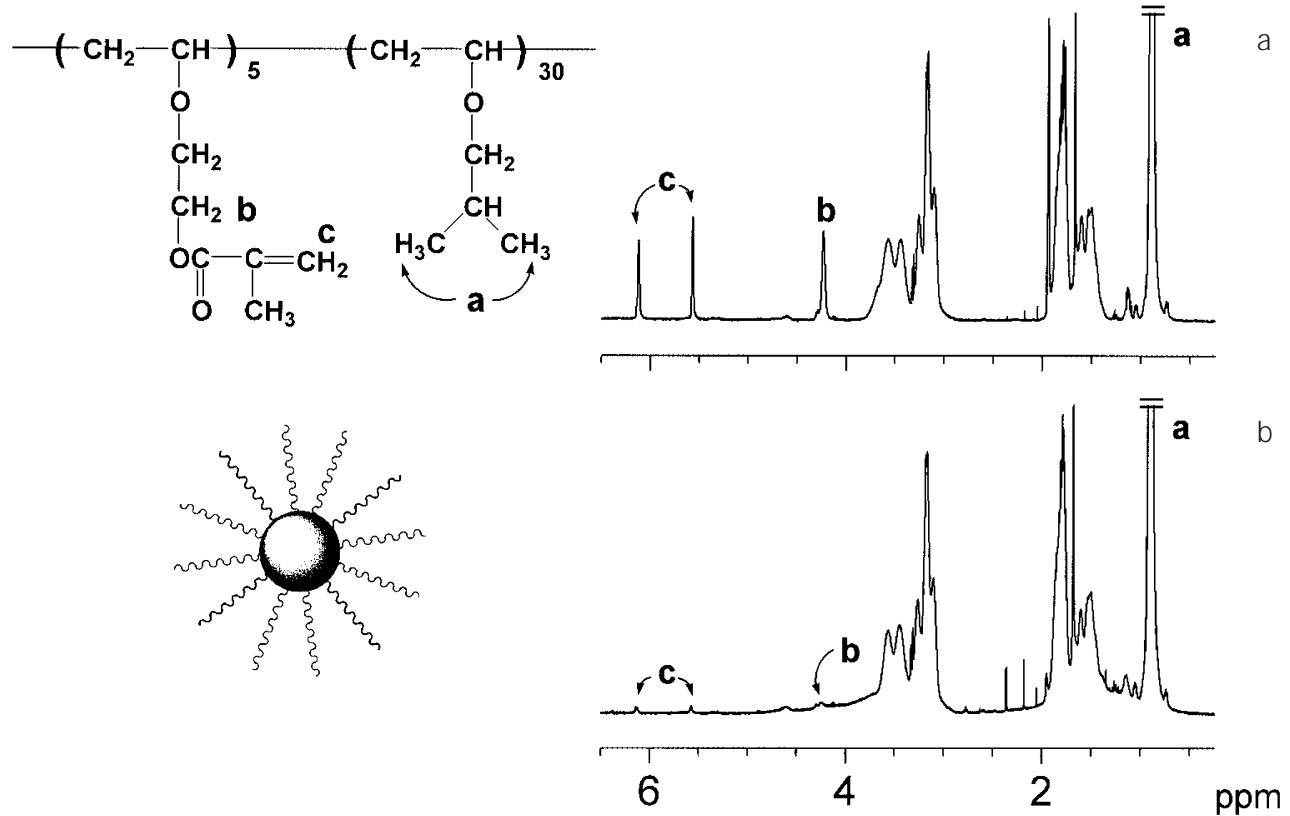

Figure 5. ${ }^{1} \mathrm{H}$ NMR spectra in $\mathrm{CDCl}_{3}$ at $25^{\circ} \mathrm{C}$ : (a) block copolymer 1 (IBVE/VEM = 30/5); (b) the product obtained $24 \mathrm{~h}$ after the addition of AIBN (star-shaped polymer 2).

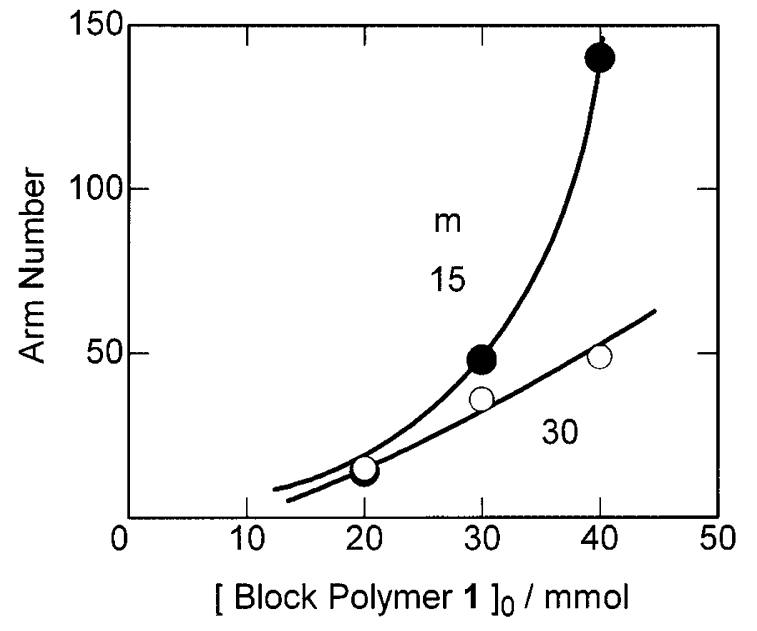

Figure 6. Relationship between the arm number $(f)$ of starshaped polymer $\mathbf{2}$ and the concentration of $\mathbf{1}$.

segment, $f$ increased with the concentration of block copolymers. A similar dependence was observed with star poly(vinyl ethers) by living cationic process. ${ }^{13}$ At a higher concentration, $f$ increased sharply as the chain length of the block copolymer was shortened. The shorter chain length of block copolymers [IBVE/VEM mol ratio $\left.=15 / 5 ; M_{\mathrm{n}}=2.76 \times 10^{3}, M_{\mathrm{w}} / M_{\mathrm{n}}=1.19\right]$ facilitate their linking reactions due to less steric hindrance. It should be noted that the arm number of star polymers by the method in this study is much larger that of star poly(vinyl ethers) via linking reactions of living polymers with divinyl compounds by cationic polymerization, ${ }^{13,14}$ although the MWD of the product polymers were broader. In the one-pot method, polymer-linking reactions becomes slow due to stable living growing ends, during which they starts to be deactivated, whereas highly reactive radical species are suited for sterically hindered polymer reactions.

\section{CONCLUSIONS}

This study has demonstrated that a facile radical polymerization process gives multibranched polymers through the linking reaction of block copolymers with 
methacrylic vinyl groups separately prepared by living cationic polymerization. The arm number and $M_{\mathrm{w}}$ of star-shaped polymers thus prepared in this study ranged from 15 to 140 , and from $3.5 \times 10^{4}$ to $34 \times 10^{4}$, respectively, which are larger than those of star polymers obtained by one-pot cationic process under similar reaction conditions, such as chain length, the number and/or concentration of vinyl groups. It should also be noted that this is a possible method to prepare a variety of functionalized nanospheres.

\section{REFERENCES}

1. a) S. Bywater, Adv. Polym. Sci., 30, 89 (1979).

b) B. J. Bauer and L. J. Fetters, Rubber Chem. Technol., 51, 406 (1978).

2. a) M. Sawamoto, S. Kanaoka, and T. Higashimura, in "HyperStructured Molecules I: Chemistry, Physics and Applications", 2nd ed., H. Sasabe, Ed., Gordon and Breach Science Publishers, Amsterdam 1999, vol. 1, p. 43.

b) S. Asthana and J. P. Kennedy, J. Polym. Sci., Part A: Polym. Chem., 37, 2235 (1999).

c) T. M. Marsalko, I. Majoros, and J. P. Kennedy, Polym. Bull., 31, 665 (1993).

3. a) K.-Y. Baek, M. Kamigaito, and M. Sawamoto, Macromolecules, 34, 7629 (2001). b) K.-Y. Baek, M. Kamigaito, and M. Sawamoto, Macromolecules, 34, 215.

c) X. Zhang, J. Xia, and K. Matyjaszewski, Macromolecules, 33, 2340 (2000).

d) J. Xia, X. Zhang, and K. Matyjaszewski, Macromolecules, 32, 4482 (1999).

4. R. S. Saunders, R. E. Cohen, S. J. Wong, and R. R. Schrock, Macromolecules, 25, 2055 (1992).

5. a) H. L. Hsieh and R. P. Quirk, Ed., "Anionic Polymerization”, Marcel Dekker, New York, N.Y., 1996, p 333.

b) J. A. Simms and H. J. Spinelli, "Macromolecular Design of Polymeric Materials", 2nd ed., K. Hatada, T. Kitayama, and O. Vogl, Ed., Marcel Dekker, New York, N.Y., 1997, p 379.

6. S. Kanaoka, Y. Fujita, and T. Higashimura, Macromol. Rapid Commun., 21, 218 (2000).

7. K. Ishizu and T. Furukawa, Polymer, 42, 7233 (2001).

8. K. Tsubaki and K. Ishizu, Polymer, 42, 8387 (2001).

9. Y. Tsukahara, S. Namba, J. Iwasa, Y. Nakano, K. Kaeriyama, and M. Takahashi, Macromolecules, 34, 2624 (2001).

10. M. Sawamoto, Trends Polym. Sci., 1, 111 (1993).

11. S. Aoshima, O. Hasegawa, and T. Higashimura, Polym. Bull., 13, 229 (1985).

12. M. Kamigaito, Y. Maeda, M. Sawamoto, and T. Higashimura, Macromolecules, 26, 1643 (1993).

13. S. Kanaoka, M. Sawamoto, and T. Higashimura, Macromolecules, 24, 2309 (1991).

14. S. Kanaoka, N. Hayase, and T. Higashimura, Polym. Bull., 44, 485 (2000). 